\begin{tabular}{|l|r|}
\hline \multicolumn{1}{|c|}{ S sciendo } & $\begin{array}{c}\text { Nordic } \\
\text { Concrete } \\
\text { Federation }\end{array}$ \\
\hline $\begin{array}{l}\text { (C) Article authors. This is an open access article distributed } \\
\text { under the Creative Commons Attribution-NonCommercial- } \\
\begin{array}{l}\text { NoDerivs licens. (http://creaticecommons.org/licenses/by.nc- } \\
\text { nd/3.0/). }\end{array}\end{array}$ & $\begin{array}{r}\text { ISSN online 2545-2819 } \\
\text { ISSN print } \quad \text { 0800-6377 }\end{array}$ \\
\hline DOI: $10.2478 /$ ncr-2021-0010 & $\begin{array}{r}\text { Received: Sept. 24, 2020 } \\
\text { Rev. received: May 27, 2021 } \\
\text { Accepted: May 28, 2021 }\end{array}$ \\
\hline
\end{tabular}

\title{
From Waste to Resource - Utilising Residue from Ready-Made Concrete as New Aggregate
}

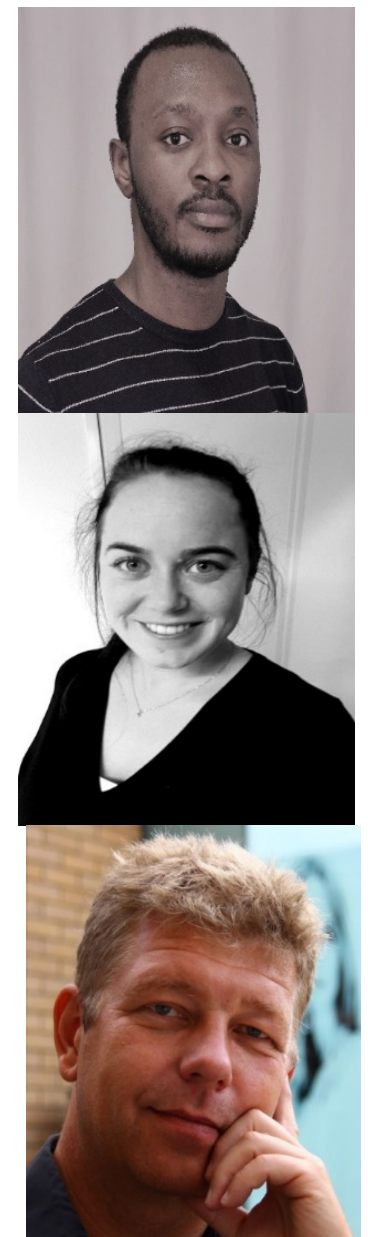

Solomon Adomako

PhD. Candidate, University of Agder

Jon Lilletuns vei 9

4879 Grimstad

Norway

solomon.adomako@uia.no

Anette Heimdal

Senior Engineer, University of Agder

Jon Lilletuns vei 9

4879 Grimstad

Norway

anette.heimdal@uia.no

\section{Rein Terje Thorstensen}

Professor, University of Agder

Jon Lilletuns vei 9

4879 Grimstad

Norway

rein.t.thorstensen@uia.no

\section{ABSTRACT}

A new admixture is available, to reduce the sludge produced from the cleansing of production and transportation equipment in the fresh concrete industry. The result is agglomerations of hardening concrete, that might be utilised for aggregate. Utilisation depends on adequate properties. This paper reports from investigations on the physical and mechanical properties of the aggregate and discussions on the performance relative to natural and recycled aggregates and towards requirements for utilisation. The findings indicate substantial potential for utilisation, supporting 
the reduction of waste for deposit and development of the concrete industry towards a circular economy.

Key words: Recycled aggregate, Admixture, Waste reduction, Circular economy

1.

\section{INTRODUCTION}

The use of concrete in the construction industry is known for massive emissions of carbon to the atmosphere, generally accepted to be responsible for 5-7\% of the world's anthropogenic carbon emissions [1]. Other environmental impacts are also related to the use of concrete. One example regards the consumption of aggregate. $60-70 \%$ of the volume of concrete is constituted by rock materials, normally extracted from natural ores. However, access to suitable natural aggregates is diminishing. According to Tam et al. [2], the global production of aggregate near doubled in seven years, from 21 billion tons in 2007 to 40 billion tons in 2014. Technologies for production of aggregate with appropriate quality and at low cost are gaining interest. Other examples of negative environmental impacts from the concrete industry are the waste of surplus fresh concrete that is produced at nearly all deliverances, and contaminated water from the rinsing of equipment for production and transportation.

According to the paper "A review of recycled aggregate in concrete applications (2000-2017)" [2], the practice of recycling materials from construction and demolition (C\&D) waste varies heavily even in closely related economies and cultural environments. In Europe, Switzerland is reported to recycle $28 \%$ of its C\&D waste, Norway $67 \%$, Belgium $86 \%$, Denmark $94 \%$, and the Netherlands $98 \%$. The global variations span even wider, with dominant economies with potential for influencing the world environment like Brazil 6\%, China 40\%, USA 48\%, Japan 81\%, and Germany $86 \%$. Generally, recycled materials are used for lower-end applications. However, examples of systematic high-end use like in structural concrete are also found. This utilisation is attributed to advanced legal systems with the ability to certify quality, exemplified by the Confirmite Europeenne (CE) Certificate. Environmental challenges are global. Recycling C\&D waste has potential for accommodating several of the world's environmental challenges. The review article is concluded with a call for parallel trajectories on research to investigate and document properties and potential, on legislation system to accommodate and secure quality, and on the market for improving acceptance level.

The investigation reported in the present paper is one part of the ongoing industrial research project RECONC, partly funded by the Research Council of Norway. The aim is to develop and document an aggregate made from surplus fresh concrete and sludge from the rinsing process of equipment. This utilisation is believed to having potential for both stopping the leach of heavy metals from deposited waste materials, and for contributing to the $\mathrm{CO}_{2}$-binding of concrete through the un-carbonised cementitious content incorporated in this aggregate.

Central in this project is a new admixture that has been developed, Re-con Zero Evo. This is a two-component powder product made from special polymers and inorganic composites. It works as a water absorber/viscosifier and a setting accelerator for concrete. The powder can be added to production and transportation equipment, causing residues of fresh concrete to agglomerate and form moist granules. The granules develop to dry agglomerations of concrete within 24 hours. Preliminary studies indicate a potential for reducing the generation of sludge by $80 \%$, compared to normal washing procedures. 
If the material properties are satisfying, the agglomerations can be utilised for aggregate. This paper reports from investigations on the physical and mechanical properties of aggregate produced through the use of this new admixture. The aggregate is denoted Ready Mixed Concrete - Residue Aggregate (RMC-RA).

\section{2.}

\section{MATERIALS AND METHODS}

A limited literature search was executed to determine material properties for recycled and natural aggregates, contexts and frequently used test regimes, including procedure requirements for applications.

For decades, the Los Angeles test (LA) and the Micro Deval test (MD) have been commonly used protocols for determining mechanical properties and the suitability of particulate materials towards diverse constructional applications. Details on each testing protocol are given in several commonly used standard regimes, like CEN and ASTM. Requirements are given in the form of highest required LA and MD values for bound use like aggregate in concrete, and unbound use like in the construction of roads. LA and MD values are normally found to be closely related to porosity and water absorption, which might be utilised for explaining variations in mechanical strength. Consequently, these four properties are often determined in parallel when investigating mechanical properties of particulate materials. Values for these properties for various types of aggregate have been extracted from available research and implemented in the discussion below to evaluate the properties determined for the RMC-RA in this investigation.

The relationship between aggregate geology and frequently used tests for determining mechanical strength is investigated in a novel review article [3]. Not surprisingly, it was found that high presence of primary minerals like quartz and feldspar correlate positively to high strength values like those from LA and MD tests. However, it was also found that not only the types of minerals influence the strength values. Properties like the size and spatial distribution of mineral grains and the shape of the aggregate particles are frequently found to correlate with strength values. Presence of up to $20 \%$ of minerals known to be weak is not found to be influential in tests like LA and MD, while rocks composed with angular morphological features experience rapid disintegration in LA and MD tests. A strong positive correlation between increasing porosity and increasing Los Angeles values was also reported in most of the papers.

A batch of RMC-RA was received from the producer of the new additive Recon Zero Evo. The batch was divided into subsamples for performing all tests according to Table 1. The whole batch was utilised for these tests.

\begin{tabular}{|c|c|c|c|}
\hline Test method & NS-EN Standard & Ref & Test Objective \\
\hline PSD & NS-EN 933-1 & [4] & Cumulative particle size distribution \\
\hline Los Angeles & NS-EN 1097-2 & [5] & Determination of resistance to fragmentation \\
\hline Micro-Deval & NS-EN 1097-1 & [6] & Determination of resistance to wear \\
\hline Flakiness Index & NS-EN 933-3 & [7] & Determination of particle shape-Flakiness index \\
\hline $\begin{array}{l}\text { Water Absorption and } \\
\text { Particle Density }\end{array}$ & NS-EN 1097-6 & [8] & $\begin{array}{l}\text { Determination of particle density and water } \\
\text { absorption }\end{array}$ \\
\hline
\end{tabular}




\section{3.}

\section{RESULTS AND DISCUSSION}

Possible leakage of harming agents is a risk necessary to investigate for all recycling of waste materials. An initial screening for potential environmental impacts from the use of RMC-RA was made part of the literature search. Deposited waste concrete and sludge from the rinsing of equipment have potential for leaching harming agents including heavy metals like $\mathrm{Pb}, \mathrm{Cd}, \mathrm{Ni}, \mathrm{Zn}$, $\mathrm{Cr} 3+$ and $\mathrm{Cr} 6+$. This is well documented through several investigations made by the Norwegian Environment Agency, which have responded by implementing requirements to restrict leaching to soil and water. On the positive side: it is also documented that hardened concrete has potential for binding $\mathrm{CO}_{2}$ from the atmosphere. According to Engelsen and Justnes [9], a binding potential of $250-330 \mathrm{~kg} \mathrm{CO}_{2}$ per unit concrete containing $1000 \mathrm{~kg}$ cement has been determined. Utilisation of recycled materials for aggregate in new concrete has been proven to reduce the risk of leaching to negligible levels.

The results from all executed measurements are shown in Figure 1 and Table 2.

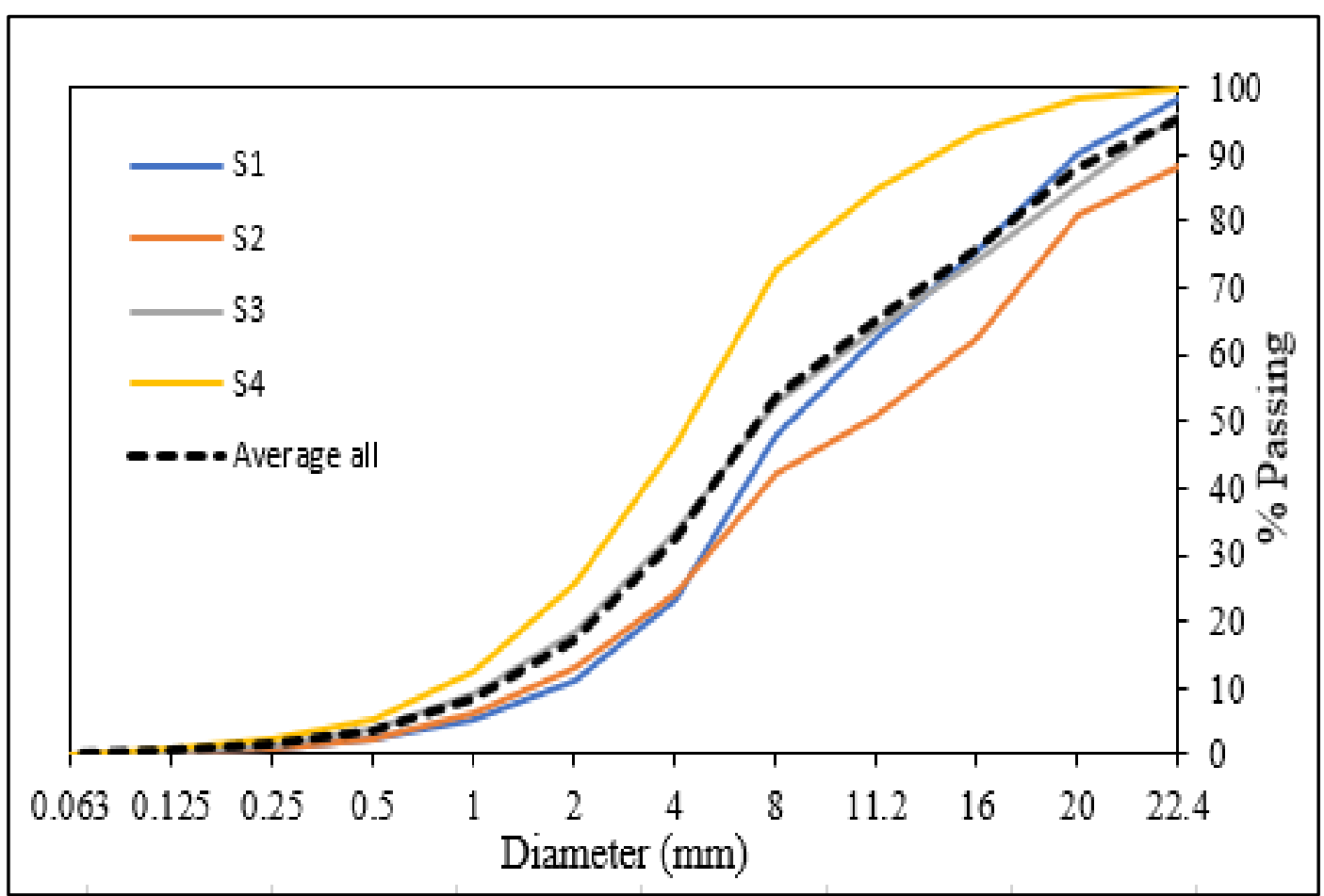

Figure 1 - Particle size distribution for the particulate material as received.

Table 2 -Numerical results from the testing of materials in the lab.

\begin{tabular}{lccccc} 
& $\begin{array}{c}\text { No of } \\
\text { Average } \\
\text { value }\end{array}$ & $\begin{array}{c}\text { parallel } \\
\text { tests }\end{array}$ & $\begin{array}{c}\text { Standard } \\
\text { deviation }\end{array}$ & $\begin{array}{c}\text { Highest } \\
\text { value }\end{array}$ & $\begin{array}{c}\text { Lowest } \\
\text { value }\end{array}$ \\
\hline Water absorption (\%) & $\mathbf{8 \%}$ & 1 & N/A & N/A & N/A \\
Density & $\mathbf{2 . 6 6}$ & 2 & 0.02 & 2.643 & 2.673 \\
Flakiness index & $\mathbf{2 0 0 \%}$ & 1 & N/A & N/A & N/A \\
Micro Deval & $\mathbf{3 1 . 4}$ & 2 & 0.6 & 31.0 & 31.8 \\
Los Angeles & $\mathbf{2 5}$ & 2 & 3.5 & 22.0 & 27.0 \\
\hline
\end{tabular}


All particles present in the received batch of material were smaller than $32 \mathrm{~mm}$. Four independent, parallel tests were executed to determine the particle size distribution according to [4]. Results from all the parallel tests are shown in Figure 1, which also includes an accumulated curve for the average of the results from all four samples.

\section{2}

\section{Water absorption (WA) and particle density ( $\left.\rho_{\text {particle }}\right)$}

The water absorption of natural aggregates is commonly accepted to be low $(0.5-1.5 \%)$, unless for rock with high content of the mineral mica. The particle density of rock types frequently found in Norway is in the range of $2.65-3.10 \mathrm{~kg} / \mathrm{dm}^{3}$. These two properties are also commonly understood to be inversely correlated. This is intuitively explained by the porosity needed to accommodate water in excess to what is bound to the aggregate surface, contribute to reducing the particle density. The mathematical relation is that the porosity $\mathrm{P}=1-\rho_{\text {total }} / \rho_{\text {compact, }}$ with $\rho_{\text {total }}=$ $\rho_{\text {particle }}$ when applied at a particle level.

The water absorption of the RMC-RA is determined to $8 \%$, and the particle density $2.66 \mathrm{~kg} / \mathrm{dm}^{3}$ (Table 2). According to Kox et al. [10], the main characteristic that separates Recycled Concrete Aggregate (RCA) from natural aggregate is water absorption. The WA of 12 different types of RCA was determined by Kox et al. to an average of 3.2\%, substantially higher than that of natural aggregate. The corresponding average density was $2.32 \mathrm{~kg} / \mathrm{dm}^{3}$, substantially lower than that of most natural aggregates. The determined particle density of the RMC-RA is higher than what Kox et al. reported for all variants of RCA. A reasonable assumption would then be that the porosity and hence the water absorption should be correspondingly low. However, the WA of RMC-RA is found to be $8 \%$ - far above the average 3.2\% determined by Kox et al. for the 12 types of RCA. One explanation might be that while the hydration process of cement in the RCA has completed a long time ago, the RMC-RA is considered applicable already a few days after the cement and the water met in the mixing process. The hydration process in the RMC-RA might still be ongoing, continuously reducing the open porosity, e.g. the portion of the pores able to exchange water with the surroundings. Thus, the apparent porosity of the RMC-RA particles, which is what is determined through the WA test, might be reduced during time because of the hydration process going on inside. An interesting follow-up investigation would be to track the development of water absorption during a time series starting from when the RMC-RA aggregate is considered ready for use and continued until a steady-state is achieved. That was not part of the program this time.

The ongoing hydration within the RMC-RA particles might directly influence the resulting water absorption measurement, according to the method described in NS-EN 1097-6. High temperature is used to evaporate the absorbed water, following the submersion for saturating. If the material is still young, mixing water from the fresh concrete might be evaporated from pores that would not have been penetrated during the standardised submersion process. This excess water would then increase the water absorption result.

Aggregate having high water absorption might be challenging to concrete mixing. All surfaces in a moist environment are covered with a thin layer of physically adsorbed water, typically 2-3 molecular thick. This explains most of the typical water absorption of aggregate, normally spanning $0.5-1.5 \%$. Water absorption of $8 \%$ must be partly attributed to capillary pores in the 
aggregate particles. If the aggregate moist level is below "Saturated Surface Dry", water will be attracted from the added water in the fresh concrete. How fast this will happen and consequently how this will influence the hydration of the cement, is depending on the diameter of the capillary pores. On the other hand, the water absorbed in the aggregate might benefit hydration as the capillary forces in the hardening concrete increase. This mechanism is referred to as "internal curing" and might be a way to increase the water content without compromising the requirements for water/cement ratio. Again, it is a question about the diameter of the capillary pores in the aggregate.

Additionally, the high potential for water absorption in the RMC-RA indicated by the determined WA value opens for increased risk of freezing-thawing damage to concrete made with this aggregate.

\section{3}

\section{Flakiness index (FI)}

The flakiness index represents a quantification of the occurrence of elongated particles in the aggregate. The higher the FI, the higher the occurrence of elongated particles. The FI of the RMCRA was determined to a value of 2 (Table 2), based on testing the complete batch received. Kox et al. [10] report FIs for the 21 different RCA materials in the range 3 to 15 , averaging on 9. The flakiness index of processed aggregate is primarily a result of the crushing process. Hence typical values specifically for different types of rock are not relevant.

However, the Norwegian Public Roads Administration (NPRA) states that the FI value of the aggregate influences both the stability in un-bound applications in road-building and the performance of concrete and asphalt. Several requirements are stated in the design code N200 "Road building" [11]; FI $<20$ being the strongest. In concrete, high FI is known to negatively impact the workability and thus requiring high water content and consequently high cement content. The hardened properties of concrete are indirectly negatively impacted by aggregate having high FI. According to the National appendix in NS-EN 206 [12], the FI should be below 35 (Table NA.4). In the NS-EN 12620 "Aggregates for concrete" [13], categories of FI are given down to the value 15. However, it is commonly known in the concrete profession that this is insufficient as for each level below this, the water and hence the cement consumption is reduced - certainly gaining the environment and probably also the economy. 


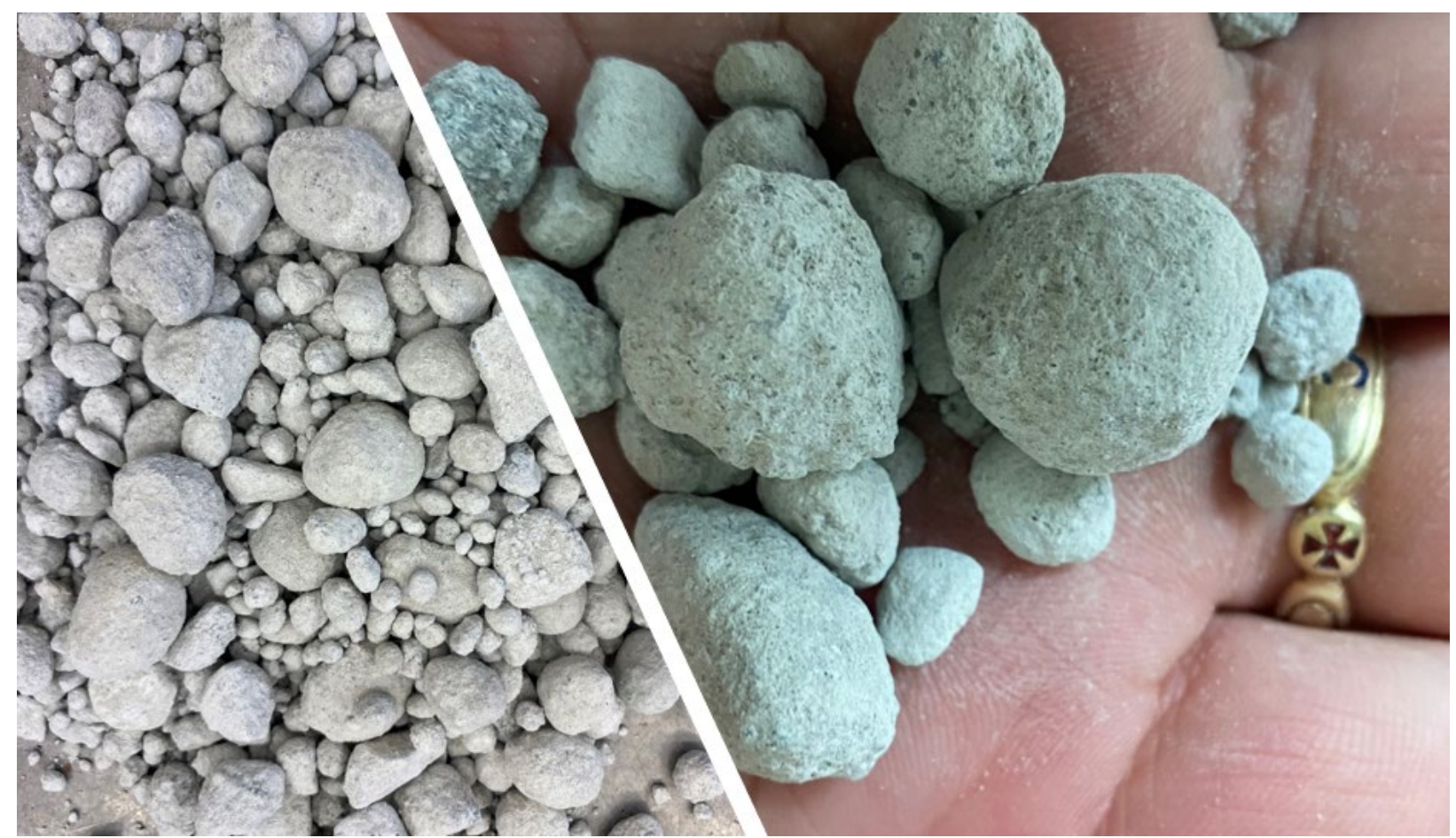

Figure 2 - The RCM-RA in bulk (left) and detail (right), scaled towards a human hand.

In contradiction to all crushed aggregates, both natural and recycled, the flakiness index of the RMC-RA is not influenced by varying production processes. However, as illustrated in Figure 3, the particles appear rounded, which is probably the result of the agglomeration process during rotation in the drum of the concrete truck. The determined value is lower than all $21 \mathrm{RCA}$ aggregates referred to in this paper and far below all requirements for use in concrete and road building. The low FI value might contribute to low water requirement when mixing concrete, and thus low cement consumption.

\section{4}

\section{Micro-Deval (MD) value}

The Micro-Deval test measures the wear resistance of aggregates in a moisturized condition. Like the LA value, the MD value represents the percentage of mass passing a $1.6 \mathrm{~mm}$ sieve subsequent to execution of the test. Hence, the lower the MD-value, the higher resistance towards wear.

The MD-value of the RMC-RA was determined through two independent, parallel tests to an average of 31.4 (Table 2). According to the NS-EN 12620 "Aggregates for concrete" [13], requirements for MD values are only applicable for concrete used as top layers in traffic areas (National appendix, table NA.2). The MD values of RCA seem to be little investigated, and consequently sparsely available. Al-Bayati et al. [14] determined the MD value of one source of RCA to the value 23.6, in an investigation on applicability for use in asphalt. The investigation reported by Erichsen et al. [15] on rock types frequently found in Norway apply the Nordic Abrasion (NA) test for determining wearing resistance, rather than the MD test. In another paper by Erichsen et al., the two methods are compared [16]. It is determined that MD and NA correspondingly differentiate between different types of aggregates. However, the NA yields slightly higher values than MD. 
According to this, the RMC-RA is found to be more prone to wear than RCA and most natural aggregates - performing like average limestone. The only limitation on use found in relevant requirements is in the National appendix for NS-EN 12620 "Aggregates for concrete". Hence, considerations towards the use of RMC-RA for top-layer concrete in traffic areas seem to be the only relevant limitation resulting from the MD value of RMC-RA.

\section{5}

\section{Los Angeles (LA) value}

The Los Angeles abrasion test is a common test to measure the resistance of the aggregate to disintegration by impact loads. The resulting LA-value is the percentage of mass that is crushed during the test procedure, down to fractions passing a $1.6 \mathrm{~mm}$ sieve. Hence, the lower the LAvalue, the higher the resistance towards disintegration.

The LA-value of the RMC-RA was determined through two parallel tests to an average value of 25 (Table 2). Kox et al. [10] investigated a set of 21 "high grade" Recycled Concrete Aggregates (RCA), sampled from different origins and crushing processes. The "high-grade" sorting refers to this being an investigation on materials suitable for use in road building according to the Flemish "Standard Tender specification 250". The LA values of the RMC-RA relative to the 21 samples determined by Kox et al. [10] and reference values for some natural rock types frequently found in Norway (according to Erichsen et al. [15]) are shown in Figure 3.

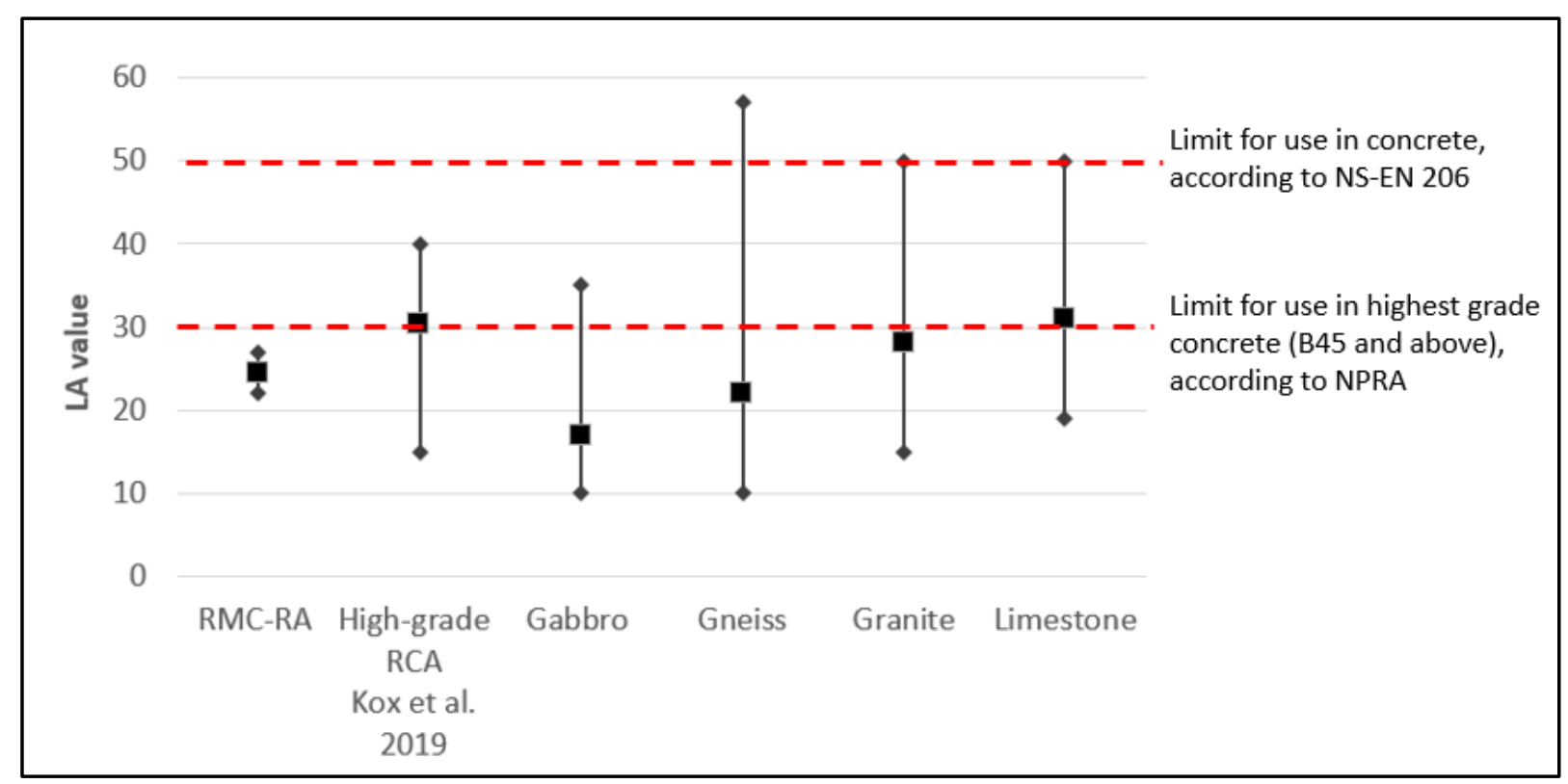

Figure $3-L A$ values for the investigated $R M C$ - $R A$ compared to recycled aggregate from crushed concrete (RCA) and some natural rock types from [15]. Boxes represent average, while the lines span to upper and lower extent.

The LA value is an important property for aggregates, used in multiple procedures and codes to limit whether materials are applicable. According to NS-EN 206 "Concrete - Specification, performance, production and conformity" [12], the LA value for coarse natural aggregate (Table E.1) and coarse recycled aggregate (Table E.3) should be below 50. The Norwegian Public Roads Administration (NPRA) requires LA value below 30 for aggregates used in the highest quality concrete applied in the Norwegian road infrastructure (B45 and above). According to our 
investigation, the RMC-RA demonstrates sufficient resistance towards disintegration for use as aggregate even in high strength concrete.

From a compositional view, it might be surprising that the LA value of RMC-RA levels that of high-quality rock types like gneiss and granite. Additionally, according to [3], LA values correlate positively with porosity. Kox et al. [10] concluded that the main characteristic that separates RCA from natural aggregate is its high water absorption, which might be taken as an indication of high porosity. Both seem confirmed by Figure 3, where the LA values for RCA are levelling that of the relatively weak rock type limestone. Both composition and determined porosity indicate that RMC-RA should be expected to have LA value levelling that of RCA and the weaker rock type. One reason for the relatively low LA value of RMC-RA might be the particle shape. Still, according to [3], particles of crushed rock composed with angular morphological features experience rapid disintegration in LA and MD tests. Both the visual in Figure 2 and the low flakiness index indicate that the RMC-RA are well rounded, with a low degree of angularity. If this is the explanation, the relative importance of particle shape to the LA test is high.

\section{4.}

\section{CONCLUSION}

The use of the admixture ReConZero for cleaning fresh concrete from mixing and transportation equipment is claimed to reduce the need for rinsing water and the production of sludge by up to $80 \%$. The resulting product is agglomerations of concrete that might be used for recycled aggregate (RMC-RA), e.g. in the production of new concrete. Reducing waste for deposit by utilising it for new production, would be an important step in the desired direction of a circular economy. According to [2], high-end structural use needs the legislation system of highly developed countries. The usability of the new product is, however, dependent on a range of physical and mechanical properties. Some have been investigated and reported in this paper.

The LA value 25 of the RMC-RA is lower ("better") than the range of 21 referred "high grade" recycled concrete aggregates (RCA) made from crushed hardened concrete waste, and well below the limit values for use in high strength concretes according to both the concrete standard NS-EN 206 and the requirements from the NPRA. A very low flakiness index of 2 is by far within the requirements for use in all types of concrete, also opening for lower cement consumption in concrete than even the best category $(\mathrm{LA}<15)$ stated in the aggregate standard NS-EN 12620.

The relatively high MD value of 31.4 of the RMC-RA calls for consciousness considering applications in concrete for the top layer in traffic areas. High WA leaves questions on the impact this might have on the mixing process of concrete, potentially creating both problems and advantages through internal curing. Also, it might cause vulnerability for freeze-thaw degrading. The high WA might be caused by a low rate of maturing of the hydration process in the RMCRA particles. Hence, the freezing-thawing vulnerability might be reduced as the cement hydration reduces the open porosity inside the particles, but this remains to be investigated. All investigations reported in this paper are limited. These conclusions should merely be considered as indications. 


\section{REFERENCES}

1. Benhelal E, Zahedi G, Shamsaei E \& Bahadori A: "Global strategies and potentials to curb $\mathrm{CO}_{2}$ emissions in cement industry". Journal of Cleaner Production, Vol. 51, 2013, pp. 142-161. doi: https://doi.org/10.1016/j.jclepro.2012.10.049.

2. Tam V W, Soomro M \& Evangelista A C J: "A review of recycled aggregate in concrete applications (2000-2017)," Construction and Building Materials, Vol. 172, 2018, pp. 272292.

3. Adomako S, Engelsen C J, Thorstensen R T \& Barbieri D M: "Review of the relationship between aggregates geology and Los Angeles and micro-Deval tests," Bulletin of Engineering Geology and the Environment, pp. 1-18, 2021.

4. NS-EN 933-1: 2012 Tests for geometrical properties of aggregates - Part 1: Determination of particle size distribution - Sieving method, CEN_Standard_Norway.

5. NS-EN 1097-2: 2010 Tests for mechanical and physical properties of aggregates. Part 2: Methods for the determination of resistance to fragmentation, CEN_Standard_Norway.

6. NS-EN 1097-1: 2011 Tests for mechanical and physical properties of aggregates Part 1: Determination of the resistance to wear (micro-Deval), CEN_Standard_Norway.

7. NS-EN 933-3:2012 Tests for geometrical properties of aggregates Part 3: Determination of particle shape Flakiness index, CEN_Standard_Norway.

8. NS-EN 1097-6:2013 Tests for mechanical and physical properties of aggregates Part 6: Determination of particle density and water absorption, CEN_Standard_Norway.

9. Engelsen $\mathrm{C} \&$ Justnes $\mathrm{H}$ : " $\mathrm{CO}_{2}$-binding by concrete-Summary of the state of the art and an assessment of the total binding of $\mathrm{CO} 2$ by carbonation in the Norwegian concrete stock". SINTEF Report SBF2014A0019, Oslo, Norway, Vol. 66, 2014.

10. Kox S, Vanroelen G, Van Herck J, de Krem H \& Vandoren B: "Experimental evaluation of the high-grade properties of recycled concrete aggregates and their application in concrete road pavement construction". Case Studies in Construction Materials, Vol. 11, 2019 , p. e00282.

11. Hand book R210: Laboratory invetigations, N. P. R. Administration, 2016.

12. NS-EN 206: 2013+A1:2016+NA:2017 Concrete - Specification, performance, production and conformity, CEN_Standard_Norway.

13. NS-EN 12620: 2002+A1:2008+NA2016 Aggregates for concrete, CEN_Standard_Norway.

14. Al-Bayati H K A, Tighe S L \& Achebe J: "Influence of recycled concrete aggregate on volumetric properties of hot mix asphalt". Resources, Conservation and Recycling, Vol. 130, 2018, pp. 200-214.

15. Erichsen E, Ulvik A, Wolden K \& Neeb P-R: "Aggregates in Norway_Properties defining the quality of sand, gravel and hard rock for use as aggregate for building purposes". Geology for Society, Geological Survey of Norway Special Publication, Vol. 11, 2008, pp. 37-46.

16. Erichsen E, Ulvik A \& Sævik K: "Mechanical degradation of aggregate by the Los Angeles-, the micro-Deval-and the Nordic test methods," Rock mechanics and rock engineering, Vol. 44, No. 3, 2011, p. 333. 